\title{
Effect of hydrochloric acid extraction on yield and gel properties of gelatine from salted jellyfish by-products
}

\author{
Wiriya Charoenchokpanich ${ }^{1}$, Pratchaya Muangrod ${ }^{1}$, Vilai Rungsardthong ${ }^{1}$, Savitri Vatanyoopaisarn ${ }^{1}$, Benjamaporn \\ Wonganu $^{2}$, Sittiruk Roytrakul ${ }^{3}$ and Benjawan Thumthanaruk ${ }^{1, *}$ \\ ${ }^{1}$ Department of Agro-Industrial Food and Environmental Technology, Faculty of Applied Science, King Mongkut's University of \\ Technology North Bangkok, Bangkok, Thailand \\ ${ }^{2}$ Department of Biotechnology, Faculty of Applied Science, King Mongkut's University of Technology North Bangkok, Bangkok, \\ Thailand \\ ${ }^{3}$ National Center for Genetic Engineering and Biotechnology, National Science and Technology Development Agency (NSTDA), \\ Pathum Thani, Thailand
}

\begin{abstract}
Salted jellyfish by-products have collagen protein that is mainly sold for animal feed at a low price. The change of jellyfish by-products into a food ingredient like gelatine could benefit food applications and reduce food waste. Indeed, jellyfish gelatine production is a time-consuming process that includes alkaline pre-treatment, acid pre-treatment, hot water extraction, and drying. Reduced times of acid pre-treatment and water extraction might deliver different gel properties. Therefore, this research aimed to investigate the effect of hydrochloric acid $(\mathrm{HCl})$ pre-treatment on the gel quality of resultant gelatine. Desalted jellyfish by-products were immersed in $0.5 \mathrm{M}$ sodium hydroxide at $4^{\circ} \mathrm{C}$ for $1 \mathrm{~h}$ and then were acidtreated by varying $\mathrm{HCl}$ concentrations $(0.1,0.2$, and $0.3 \mathrm{M})$ at $25^{\circ} \mathrm{C}$ for $2 \mathrm{~h}$. After that, samples were extracted at $60^{\circ} \mathrm{C}$ for $3 \mathrm{~h}$ and dried at $60^{\circ} \mathrm{C}$ for 3 days. Results showed that gelatine yield significantly increased with increasing $\mathrm{HCl}$ concentration. Gelatine yield were $2.97 \pm 0.97 \%, 5.60 \pm 1.01 \%$, and $6.34 \pm 1.08 \%$, after extraction with $0.1,0.2$, and $0.3 \mathrm{M} \mathrm{HCl}$, respectively. Gel strength generally decreased as $\mathrm{HCl}$ concentration increased. Gel strength values were in the range of 118.89-223.60 g. The colour of jellyfish gelatine showed light to dark brown with no differences in Hue values. Thus, the short duration of $\mathrm{HCl}$ pre-treatment for $2 \mathrm{~h}$ and hot water extraction for $3 \mathrm{~h}$ was insufficient for the jellyfish gelatine process.
\end{abstract}

Keyword. Salted jellyfish by-products, Gelatine, Pre-treatment, Yield, Gel strength

\section{Introduction}

Gelatine is a protein-type hydrocolloid widely utilised in food industries, functioning as gelling, thickening stabilising, foaming, emulsifying, water binding, and crystal growth modifying [1-3]. Gelatine is derived from the denaturation of collagen [4]. Commercial gelatines are mainly produced from bovine bone and porcine skin [5]. However, bovine and porcine gelatine have faced some constraints related to religious issues and biological contaminants [6]. Therefore, alternative gelatine derived from marine animals, especially from fish, has been sold and substituted for bovine and porcine gelatines.

Many marine animals have been researched as alternative gelatine sources, especially from the byproducts of a particular industry. Interestingly, the functional qualities of marine gelatine can be comparable to mammalian gelatine to some extent [7]. However, fish gelatine generally has lower gel strength than commercial bovine and porcine gelatines [8]. To date, several studies have reported gelatine extracted from marine by-products, including clown featherback [8], blacktip shark [9], brown-banded bamboo shark [9], salmon [10], tuna [11], and squid [12]. In general, gelatine production is a time-consuming process depending on the type of raw material, type of chemicals, duration time used for the alkaline and acid pre-treatments, water extraction, and drying. However, the previous studies took a long time for acid extraction ranging from 6 to $12 \mathrm{~h}$. No study has been used to shorten the time for acid extraction, which could minimise the duration time of gelatine production.

Apart from marine species, jellyfish, which main protein is collagen and consists of little fat and cholesterol [13-15], have gained much attention for gelatine extraction. Jellyfish-based foodstuff is generally known as delicacies in Asian countries [16] which has recently gained attention in European countries [17] due to its unique jelly, crunchy texture, and its richness in collagen protein $[16,18]$. As a consequence, the demand and preference for jellyfish as a portion of food has increased worldwide. The fresh jellyfish has been preserved with salt chemicals by professional fishermen and jellyfish companies. Salted jellyfish by-products are generated from various stages of the dehydration process [19]. In general, most salted jellyfish by-products have been sold for feed meals at a low price [19]. Research on

* Corresponding author: benjawan.t@sci.kmutnb.ac.th 
jellyfish gelatine has been reported with a lower yield and gel strength than commercial gelatines (bovine and fish gelatine) $[13-15,20]$. In addition, the drawback of jellyfish gelatine is not being able to retain the gel structure at room temperature $[15,20]$. Upon jellyfish gelatine research (Fig. 1), chemicals used for pretreatment and the extraction condition of temperature and time $[12,13,20]$ affecting gelatine quality and yield have been reported elsewhere. The jellyfish gelatine extracted with $0.1 \mathrm{M} \mathrm{HCl}$ at $60^{\circ} \mathrm{C}$ for $12 \mathrm{~h}$ showed a maximum gel strength of $323.74 \mathrm{~g}$ [20]. According to the previous result, during the gelatine extraction, factors of the acid pre-treatment step and hot water extraction for a particular time could influence collagen extractability [21]. Therefore, this research aimed to investigate the reduced time process of gelatine extraction by the varying conditions of $\mathrm{HCl}$ concentrations $(0.1,0.2$, and $0.3 \mathrm{M})$ for only $2 \mathrm{~h}$ and hot water extract at $60^{\circ} \mathrm{C}$ for only $3 \mathrm{~h}$ on yield and gel quality of the resultant gelatine.

\section{Materials and methods}

\subsection{Preparation of desalted jellyfish by-products}

Salted jellyfish by-products (Lobonema smithii) were obtained from Mahachai Food and Trading Co., Ltd., Samut Sakhon, Thailand. The by-products were stored in polyethylene bags, transported to the lab at King Mongkut's University of Technology North Bangkok, Thailand, and kept refrigerated until use. For the experiment, the jellyfish material was prepared with slight modifications [19, 22]. First, the material was mechanically washed with water by a washing machine at a ratio of 1:10 (w/v) at 2 cycles. Each cycle was set for $15 \mathrm{~min}$. The sample was then drained for $10 \mathrm{~min}$ and ready for the next step of gelatine production.

\subsection{Preparation of jellyfish gelatine}

Fig. 1 displays the production of jellyfish gelatine. The gelatine production was modified according to the method of Lueyot et al. [20]. In this study, the gelatine preparation consists of multi-steps, including alkaline pre-treatment, washing, acid pre-treatment, washing, water extraction, and drying. Firstly, $1 \mathrm{~kg}$ of the desalted jellyfish by-products was continuously stirred with 0.05 $\mathrm{M} \mathrm{NaOH}$ solution in the ratio of $1: 3(\mathrm{w} / \mathrm{v})$ at $4^{\circ} \mathrm{C}$ for $1 \mathrm{~h}$ using a shaking incubator (WIS-20R, WiseCube, Korea) at $150 \mathrm{rpm}$. The sample was washed with tap water until neutral $\mathrm{pH}(6.5-7.0)$. The sample was agitated in $\mathrm{HCl}$ solution in a ratio of $1: 2(\mathrm{w} / \mathrm{v})$ at $25^{\circ} \mathrm{C}$ for $2 \mathrm{~h}$ at a speed of $150 \mathrm{rpm}$. Three different $\mathrm{HCl}$ conditions of $0.1,0.2$, and $0.3 \mathrm{M}$ were compared at this step. The $\mathrm{HCl}$ solution was changed every $60 \mathrm{~min}$. Next, the swollen sample was thoroughly washed with tap water until the sample had neutral $\mathrm{pH}$. After that, the sample was extracted with distilled water at $60^{\circ} \mathrm{C}$ for $3 \mathrm{~h}$ with a sample to water ratio of $1: 2(\mathrm{w} / \mathrm{v})$ in a temperature-controlled water bath shaker (Memmert, Schwabach, Germany) at a speed of
$100 \mathrm{rpm}$. Then, the sample was filtered using a Buchner funnel with Whatman No. 4 filter paper. Finally, the sample was dried with a tray dryer (ED 400, Binder, U.S.A.) at $60^{\circ} \mathrm{C}$ for 3 days. The obtained jellyfish gelatine samples were calculated for yield and subjected to further analysis. Each experiment was performed in triplicate.

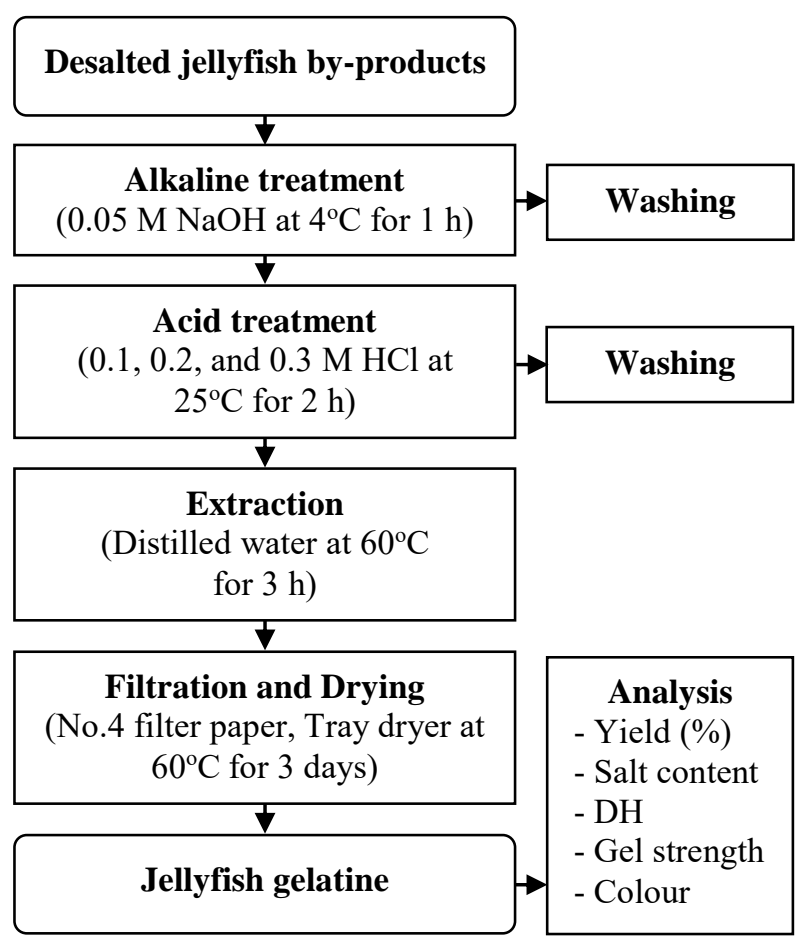

Fig. 1. Gelatine extraction from jellyfish.

\subsection{Analysis}

\subsubsection{Chemical composition}

The chemical composition of desalted jellyfish byproducts was determined protein, ash, fat, and moisture content according to the AOAC standard methods [23]. The protein content was determined by the Kjeldahl method by using a factor of 5.55 to convert the nitrogen value to protein $[23,24]$. The ash content, fat content, and moisture content were determined using the muffle furnace method, the Soxhlet extraction method, and the oven drying method, respectively [23].

\subsubsection{Yield}

The gelatine yield was calculated for all the treatments on a dry weight basis based using the following eq (1):

$$
\text { Yield }(\%)=\left(M_{2} / M_{1}\right) \times 100
$$

where $\mathrm{M}_{1}=$ Weight of the oven-dried salted jellyfish (g) and $\mathrm{M}_{2}=$ Weight of the oven-dried gelatine $(\mathrm{g})$

\subsubsection{Salt content}

The salt (sodium chloride) content of jellyfish gelatine solution after filtration $(200 \mathrm{~mL})$ was measured with a 
conductivity meter (TDS Meter 308, Systronics, India). The calculation of the percentage of sodium chloride was extrapolated from the standard curve.

\subsubsection{Degree of hydrolysis}

The sample used for DH determination was the sample before drying, followed by the previous report [25]. The jellyfish gelatine solution after filtration $(125 \mu \mathrm{L})$ was mixed with $1 \mathrm{~mL}$ of $0.01 \%$ TNBS solution and $2 \mathrm{~mL}$ of phosphate buffer $\left(\mathrm{pH} \mathrm{8.2)}\right.$ ) and incubated at $50^{\circ} \mathrm{C}$ for 30 min in the dark using a temperature-controlled water bath (WNB 45, Memmert, Germany). The reaction was terminated by adding $2 \mathrm{~mL}$ of $0.1 \mathrm{M}$ sodium sulphite and cooling at room temperature for $15 \mathrm{~min}$. The absorbance was measured at $420 \mathrm{~nm}$ using a spectrophotometer (SP 830 plus, Metertech, Taiwan). The percentage of $\mathrm{DH}$ was calculated according to the following equation (2):

$$
D H(\%)=\left[\left(L-L_{\mathrm{b}}\right) /\left(L_{\max }-L_{\mathrm{b}}\right)\right] \times 100
$$

where $\mathrm{L}=$ The $\alpha$-amino groups content of hydrolysate sample, $\mathrm{L}_{\mathrm{b}}=$ The $\alpha$-amino groups content in the original substrate (blank), and $\mathrm{L}_{\max }=$ The total $\alpha$-amino groups the sample hydrolysed by $6 \mathrm{~N} \mathrm{HCl}$ at $100^{\circ} \mathrm{C}$ for $24 \mathrm{~h}$.

\subsubsection{Determination of gel strength}

The gelatine gel was prepared slightly modified according to the standard method [26]. The dried gelatine sample was dissolved in distilled water at $60^{\circ} \mathrm{C}$ and continuously stirred until gelatine was solubilised completely to obtain the final concentration of $6.67 \%$ $(\mathrm{w} / \mathrm{v})$. The gelatine sample $(6.67 \%)$ was poured in a container with the size of $2.5 \mathrm{~cm}$ in height and $3 \mathrm{~cm}$ in diameter and then refrigerator at $4^{\circ} \mathrm{C}$ for $18 \mathrm{~h}$ before analysis. The gel strength was determined using a texture analyser (TA-XT2i, Stable Micro Systems, UK) equipped with a $1.27 \mathrm{~cm}$ diameter flat-faced cylindrical Teflon plunger $(\mathrm{P} / 0.5 \mathrm{R})$. The parameter of pre-test and post-test speeds were set at 1.5 and $1.0 \mathrm{~mm} / \mathrm{s}$, respectively. The maximum force was expressed to be defined as the gel strength $(\mathrm{g})$. The gel strength of jellyfish gelatine was compared to commercial fish and bovine gelatine (McGarrett, JR F\&B Co., Ltd, Thailand).

\subsubsection{Colour measurement}

The colour of jellyfish gelatine gel prepared at $6.67 \%$ (w/v) was evaluated by CIE L* a* b* system and measured using a colourimeter (ColorQUEST 45/0, HunterLab, USA). The results of the CIE L*a*b* colour parameters were displayed as $\mathrm{L}^{*}$ (lightness $\left.0-100\right)$, a* (redness $(+)$ /greenness $(-)$ ), and $\mathrm{b}^{*}$ (yellowness $(+) /$ blueness $(-))$. The colour of jellyfish gelatine was compared to commercial fish and bovine gelatine (McGarrett, JR F\&B Co., Ltd, Thailand). The hue angle of the sample was calculated according to the following equation (3):

$$
\text { Hue angle }=\tan ^{-1}\left(b^{*} / a^{*}\right)
$$

\subsection{Statistical analysis}

All experiments were performed in triplicate, except for the gel strength and colour determination performed in quintuplicate. The data were subjected to analysis of variance (ANOVA) and Duncan's multiple range test for statistical significance $(\mathrm{p}<0.05)$ using the statistical package for social science (SPSS) 22.0.

\section{Results and discussions}

\subsection{Quality of desalted jellyfish by-products}

The desalted jellyfish by-products had protein, ash, fat, and moisture content of $8.68 \pm 0.19 \%, 1.04 \pm 0.23 \%$, $0.98 \pm 0.08 \%$, and $89.10 \pm 0.10 \%$, respectively. These results were slightly different from other studies, which reported that the desalted jellyfish (Lobonema smithii) (washed 2 cycles) had protein, ash, fat, and moisture content of $4.79-5.55 \%, 1.19-1.39 \%, 0.91-0.95 \%$, and $91.86-93.36 \%$, respectively $[19,22]$. Differences in proximate results might be due to differences in the seasonal catch or varying salting process [22]. Despite no determination of collagen in this study, previous reports showed that most of the jellyfish proteins were collagen protein $[16,27,28]$.

\subsection{Effect of pre-treatment with different $\mathrm{HCl}$ concentrations on yield, salt content, and DH}

\subsubsection{Yield}

After pre-treatment with $0.1,0.2$, and $0.3 \mathrm{M} \mathrm{HCl}$, the yields of jellyfish gelatine were $2.97 \%, 5.60 \%$, and $6.34 \%$, respectively, calculated on a dry weight basis (Table 1). The gelatine yield significantly increased with increased $\mathrm{HCl}$ concentration from 0.1 to $0.2 \mathrm{M}$ but not with $0.3 \mathrm{M} \mathrm{HCl}$. However, the jellyfish gelatine yields of this study showed lower values from the other works with different types and concentrations of acid used and extraction temperature and time. The highest yield of type A jellyfish gelatine was $39.47 \%$ (on a dry weight basis) when pre-treated with a sulfuric acid solution ( $\mathrm{pH}$

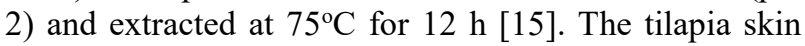
gelatine pre-treated with $0.1 \mathrm{M} \mathrm{NaOH}$ and extracted at $55^{\circ} \mathrm{C}$ for $6 \mathrm{~h}$ showed the highest yield of $21.10 \%$ on a dry weight basis) [29]. The highest yield of blacktip shark and the brown-banded bamboo shark was 21.17$24.76 \%$ and $19.06-22.81 \%$ (based on wet weight), respectively when pre-treated with a $0.1 \mathrm{M} \mathrm{NaOH}, 1 \mathrm{M}$ $\mathrm{HCl}$, and $0.2 \mathrm{M}$ acetic acid and extracted at 45, 60, and $75^{\circ} \mathrm{C}$ for 6 and $12 \mathrm{~h}$ [9]. Thus, compared to the yields from other studies, the shortened duration of $\mathrm{HCl}$ pretreatment for only $2 \mathrm{~h}$ and hot water extraction for $3 \mathrm{~h}$ was insufficient for the jellyfish gelatine process due to the leftover jellyfish by-products greater than $90 \%$ remained. 
Table 1. Yield, salt content, and degree of hydrolysis of jellyfish gelatine at different $\mathrm{HCl}$ concentrations pre-treatment.

\begin{tabular}{|c|c|c|c|c|}
\hline Sample & Yield* $(\%)$ & Conductivity* (us/cm) & $\mathrm{NaCl}$ content* $(\%)^{2}$ & $\mathrm{DH}^{*}(\%)$ \\
\hline $0.1 \mathrm{M} \mathrm{HCl}$ & $2.97 \pm 0.97^{\mathrm{b}}$ & $1,029.67 \pm 4.72^{\mathrm{a}}$ & $0.047 \pm 0.00^{\mathrm{a}}$ & $29.74 \pm 0.6^{\mathrm{c}}$ \\
\hline $0.2 \mathrm{M} \mathrm{HCl}$ & $5.60 \pm 1.01^{\mathrm{a}}$ & $996.67 \pm 5.50^{\mathrm{b}}$ & $0.046 \pm 0.00^{\mathrm{b}}$ & $33.63 \pm 0.45^{\mathrm{b}}$ \\
\hline $0.3 \mathrm{M} \mathrm{HCl}$ & $6.32 \pm 1.08^{\mathrm{a}}$ & $947.33 \pm 2.08^{\mathrm{c}}$ & $0.043 \pm 0.00^{\mathrm{c}}$ & $36.47 \pm 0.68^{\mathrm{a}}$ \\
\hline
\end{tabular}

*Different superscript letters in the same column indicate a significant difference $(\mathrm{p}<0.05)$.

Table 2. Gel strength and colour of jellyfish gelatine at different $\mathrm{HCl}$ concentrations pre-treatment and commercial gelatines (bovine and fish gelatine).

\begin{tabular}{|l|c|c|c|c|c|}
\hline \multirow{2}{*}{ Sample } & \multirow{2}{*}{ Gel strength* $(\mathrm{g})$} & \multicolumn{4}{|c|}{ Colour* } \\
\cline { 3 - 6 } & & $\mathrm{L}^{*}$ & $\mathrm{a}^{*}$ & $\mathrm{~b}^{*}$ & $\mathrm{~h}^{*}$ \\
\hline $0.1 \mathrm{M} \mathrm{HCl}$ & $223.61 \pm 3.72^{\mathrm{c}}$ & $4.43 \pm 0.61^{\mathrm{cd}}$ & $5.68 \pm 0.44^{\mathrm{a}}$ & $8.64 \pm 0.32^{\mathrm{a}}$ & $33.05 \pm 2.46^{\mathrm{a}}$ \\
\hline $0.2 \mathrm{M} \mathrm{HCl}$ & $214.47 \pm 4.12^{\mathrm{c}}$ & $5.70 \pm 0.93^{\mathrm{bd}}$ & $5.71 \pm 0.53^{\mathrm{a}}$ & $9.01 \pm 0.66^{\mathrm{a}}$ & $32.43 \pm 3.81^{\mathrm{a}}$ \\
\hline $0.3 \mathrm{M} \mathrm{HCl}$ & $118.89 \pm 0.48^{\mathrm{d}}$ & $7.24 \pm 1.18^{\mathrm{b}}$ & $5.94 \pm 0.02^{\mathrm{a}}$ & $9.19 \pm 0.85^{\mathrm{a}}$ & $32.98 \pm 2.31^{\mathrm{a}}$ \\
\hline Bovine & $358.62 \pm 3.42^{\mathrm{a}}$ & $16.76 \pm 2.39^{\mathrm{a}}$ & $0.71 \pm 0.46^{\mathrm{c}}$ & $-9.66 \pm 1.08^{\mathrm{b}}$ & $3.98 \pm 2.27^{\mathrm{b}}$ \\
\hline Fish & $306.11 \pm 3.79^{\mathrm{b}}$ & $3.67 \pm 1.10^{\mathrm{d}}$ & $4.92 \pm 0.41^{\mathrm{b}}$ & $-9.90 \pm 0.37^{\mathrm{b}}$ & $26.45 \pm 2.69^{\mathrm{c}}$ \\
\hline
\end{tabular}

*Different superscript letters in the same column indicate a significant difference $(\mathrm{p}<0.05)$.
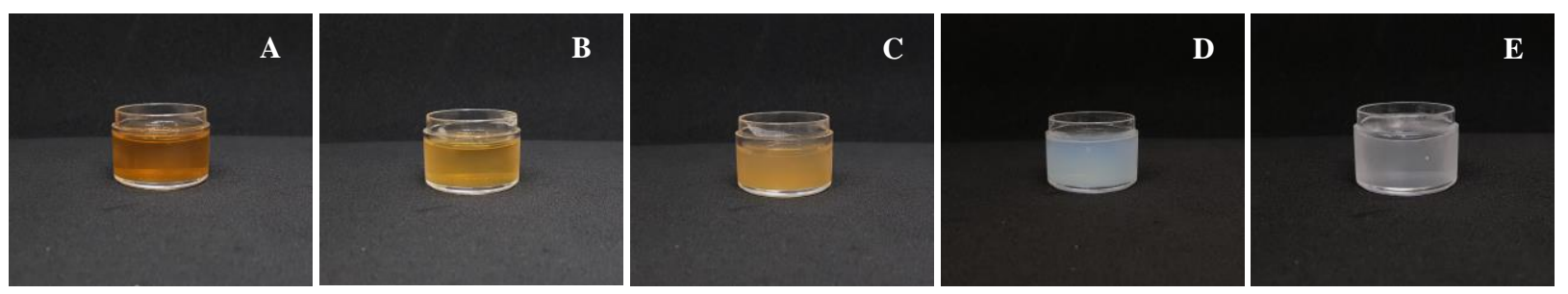

Fig. 2. Gelatine gel (A) jellyfish gelatine gel pre-treated at $0.1 \mathrm{M} \mathrm{HCl}$, (B) jellyfish gelatine gel pre-treated at $0.2 \mathrm{M} \mathrm{HCl}$, (C) jellyfish gelatine gel pre-treated at $0.3 \mathrm{M} \mathrm{HCl}$, (D) commercial bovine gelatine gel, and (E) commercial fish gelatine gel.

\subsubsection{Conductivity and salt content}

The effect of electrolytes has directly influenced gelatine gel quality. For the jellyfish gelatine process, increased $\mathrm{HCl}$ concentration decreased conductivity and sodium chloride. The conductivity value and sodium chloride of jellyfish gelatine solutions were in the range of 947.33$1,029.67 \mu \mathrm{s} / \mathrm{cm}$ and $0.047-0.043 \%$, after pre-treatment with $0.1,0.2$, and $0.3 \mathrm{M} \mathrm{HCl}$ (Table 1). Before washing, the sample used in this study was salted jellyfish that was cured by sodium chloride $(\mathrm{NaCl})$, sodium bicarbonate $\left(\mathrm{NaHCO}_{3}\right)$, and potassium alum sulfate $\left(\mathrm{KAl}\left(\mathrm{SO}_{4}\right)_{2}^{-}\right)$. Previous studies reported that the salt content, determined by the titration method, of the salted jellyfish before and after washing for two cycles was $14 \%$ and $1 \%$, respectively, but elements of $\mathrm{Na}, \mathrm{Al}, \mathrm{Si}, \mathrm{P}$, $\mathrm{S}, \mathrm{Cl}, \mathrm{K}, \mathrm{Ca}, \mathrm{Fe}$, and $\mathrm{Br}$ were also found in washed samples $[19,22]$. The salt elements remained in the protein structure of desalted jellyfish via the binding of positively charged ions (e.g., $\mathrm{Na}^{+}, \mathrm{K}^{+}, \mathrm{Al}^{3+}, \mathrm{Ca}^{2+}, \mathrm{Fe}^{2+}$ ) and negatively charged ions (e.g., $\mathrm{Cl}^{-}, \mathrm{Si}^{-}, \mathrm{Br}^{-}, \mathrm{PO}_{4}{ }^{3-}$ ) to the negatively and positively charged amino acids in the jellyfish protein structure $[22,30]$. Collagen in the salted jellyfish found 7 polar amino acids, including charged acidic amino acids (aspartic acid and glutamic acid), charged basic amino acids (arginine and lysine) and uncharged amino acids (serine, threonine, and tyrosine), and 10 nonpolar amino acids including alanine, cysteine, glycine, hydroxyproline, isoleucine, leucine, methionine, phenylalanine, proline, and valine [17]. All charged polar amino acids can be engaged in ionic bonds via electrostatic attraction, and all uncharged amino acids can be formed hydrogen bonds. In this study, during the gelatine process, it was noticed that the swollen jellyfish protein structure increased as the $\mathrm{HCl}$ concentration increased. As a result, in the system, the increases of $\mathrm{H}^{+}$ ion and $\mathrm{Cl}^{-}$ion might affect the charged and uncharged amino acids, causing the unfolded triple helix structure of collagen and increased binding water molecules to denatured jellyfish collagen [30]. Thus, the excess $\mathrm{Cl}^{-}$ ion might be reformed into $\mathrm{NaCl}$, thereby reducing the salt content from the swollen collagen structure. In addition, the salt was diluted during the washing step. The effect of salt on fish gelatine showed that $1.5 \%$ 
$\mathrm{NaCl}$ addition caused a loss in molecular order in secondary structure, affecting low gel strength [31]. Therefore, it is necessary to remove the excessive salt content before the drying step that might be interfering with the gel property.

\subsection{3 $\mathrm{DH}$}

The DH of jellyfish gelatine solutions increased significantly with increasing $\mathrm{HCl}$ concentration. The results showed that $\mathrm{DH}$ of jellyfish gelatine was in the range of 29.74-36.47\% (Table 1). The highest DH of jellyfish gelatine was pre-treated with $0.3 \mathrm{M} \mathrm{HCl}$, which was lower than other reports that used 1 and $6 \mathrm{~N} \mathrm{HCl}$ for 12 and $24 \mathrm{~h}$ and heated at $95^{\circ} \mathrm{C}$, yielding high $\% \mathrm{DH}$ of 73.70 and 75.40 [32]. The different chemicals affected $\mathrm{DH}$. When pre-treated with a sulfuric acid solution $(\mathrm{pH}$ 2) and extracted at 60 and $75^{\circ} \mathrm{C}$ for 6 and $12 \mathrm{~h}, \mathrm{DH}$ of jellyfish gelatine values were $65.30-77.13 \%$ [15]. During $\mathrm{HCl}$ treatment, the triple helix structure of jellyfish collagen was denatured with a higher $\mathrm{HCl}$ concentration by breaking down the hydrogen and covalent bonds [33], resulting in increased helix-to-coil transition and converted to soluble gelatine. Thus, the condition used in this study was relatively mild, compared to other studies $[14,15]$, and the shorten acid pre-treatment and water extraction. This condition might not be applicable for producing jellyfish gelatine when the desalted jellyfish was used as a raw material.

\subsection{Gel strength of gelatine gel}

Gelatine gel is a biopolymer network that is reversibly crosslinked and primarily stabilised by hydrogen-bonded junction zones [34]. Gel strength affects the texture quality in food products [14]. The gel strength of $6.67 \%$ jellyfish gelatine gel pre-treated at different $\mathrm{HCl}$ concentrations is shown in Table 2 . The jellyfish gelatine decreased gel strength values from 223.61, 214.47, and $118.89 \mathrm{~g}$ when increased $\mathrm{HCl}$ concentration from 0.1, 0.2 , and $0.3 \mathrm{M} \mathrm{HCl}$. The gel strength of jellyfish gelatine was pre-treated with $0.1 \mathrm{M} \mathrm{HCl}$, which was significantly different from those with 0.2 and $0.3 \mathrm{M} \mathrm{HCl}$, while gel strength of jellyfish gelatine was pre-treated at 0.2 and $0.3 \mathrm{M} \mathrm{HCl}$ did not show significantly different. The gel strength values of jellyfish were lower than those of bovine gelatine $(358.62 \mathrm{~g})$ and fish gelatine $(306.11 \mathrm{~g})$. Previous studies reported that jellyfish gelatine's gel strength was inferior to bovine and fish gelatine due to differences in collagen type, amino acid composition, the alpha and beta chain ratio in the gelatine, and the gelatine peptides of the alpha chain [20]. However, the gel strength of jellyfish gelatine gel, in this study, was higher than the gel strength values of Cuttlefish (Sepia Officinalis) skins (198 g) [35] and squid (Loligo formosana) skins (156 g) [4]. Compared to the same jellyfish sample, the jellyfish gel strength reported in this study was higher than the previous work that showed the gel strength of 18-118 g [14, 15]. Recently, the highest gel strength of jellyfish (Lobonema smithii) gelatine was $323.74 \mathrm{~g}$ [20] which applied a higher extraction time of
$12 \mathrm{~h}$. As a result, the concentration of $\mathrm{HCl}$ pre-treatment, pre-treatment time, and water extraction time directly affected the gel strength. Therefore, in this study, applying a mild concentration of $\mathrm{HCl}(0.1 \mathrm{M})$ for $2 \mathrm{~h}$ and shortening hot water extraction time for only $3 \mathrm{~h}$ might not be suitable for the jellyfish gelatine process. Despite low gel strength, jellyfish gelatine might be used in frozen and refrigerated food products and used for crystal growth modification.

\subsection{Colour of gelatine gel}

The colour of jellyfish gelatine gel (6.67\%) pre-treated at different $\mathrm{HCl}$ concentrations, commercial bovine gelatine gel, and commercial fish gelatine gel are presented in Table 2. The colour of gelatine gel was expressed as lightness $\left(\mathrm{L}^{*}\right)$, redness $\left(\mathrm{a}^{*}\right)$, yellowness $\left(\mathrm{b}^{*}\right)$, and hue angle $\left(\mathrm{h}^{*}\right)$. The lightness, redness, and yellowness value of jellyfish gelatine gel increased significantly with increasing $\mathrm{HCl}$ concentration. The change of redness and yellowness value related to hue angle $\left(\mathrm{h}^{*}\right)$ of gelatine gel. The colour of jellyfish gelatine showed light to dark brown (tata. 2) with no differences in hue values that were $33.05 \pm 2.46,32.43 \pm 3.81$, and $32.98 \pm 2.31$ after pre-treatment with $0.1,0.2$, and $0.3 \mathrm{M}$ $\mathrm{HCl}$, respectively. The colour of commercial bovine gelatine gel and commercial fish gelatine gel showed a transparent gel (Fig. 2) which the hue value was $3.98 \pm 2.27$ and $26.45 \pm 2.69$.

The intense brown of jellyfish gelatine gel could be due to a non-enzymatic browning reaction (Maillard reaction), in which reducing sugars, possibly ribose and deoxyribose that typically found in RNA and DNA [36], react with a free amino acid at the appropriate conditions of temperature during jellyfish gelatine drying [37]. Indeed, the drying condition for 3 days at $60^{\circ} \mathrm{C}$ might be too long, and no bleaching step was performed during jellyfish gelatine extraction. Then, the effect of the bleaching agent on jellyfish gelatine could be further studied.

\section{Conclusion}

Jellyfish by-products can be a source of gelatine production which reduced food waste and save time. The stepwise pre-treatment, including sodium hydroxide, hydrochloric acid, and hot water extraction, directly impacts gelatine qualities. The jellyfish treated with 0.1 $\mathrm{M} \mathrm{HCl}$ showed the highest gel strength of $223.61 \mathrm{~g}$ but showed the lowest gelatine yield of $2.97 \%$. The colour of jellyfish gelatine gel was light to intense brown colour compared to clear gelatine gel from fish and bovine gelatine. Therefore, improved jellyfish gelatine properties, including yield, colour, and gel strength, are still needed for further study.

\section{Acknowledgement}

This research has been financially supported by the KMUTNBNSTDA High-Performance Post Graduate Scholarship in Science and Technology (Contract no. B.021-2563) and the 
National Research Council of Thailand through the NRCT Senior Research Scholar Program (Contract no. 814-2020). The authors would like to thank Mahachai Food and Trading Co., Ltd., Samut Sakhon, Thailand, for their kind support of salted jellyfish.

\section{References}

1. S. Sultana, M.E. Ail, M.N.U. Ahamad, in Preparation and Processing of Religious and Cultural Foods, edited by M.E. Ail, N.N.A. Nizar (Woodhead Publishing, Massachusetts, 2018), pp. 215-239

2. L.M. Kasankala, Y. Xue, Y. Weilong, S.D. Hong, Q. He, Optimization of gelatin extraction from grass carp (Catenopharyngodon idella) fish skin by response surface methodology, Bioresource Technology, 98, 17 (2007): 3338-3343

3. P. Kittiphattanabawon, S. Benjakul, W. Visessanguan, F. Shahidi, Cryoprotective effect of gelatin hydrolysate from blacktip shark skin on surimi subjected to different freeze-thaw cycles, Lebensmittel-Wissenschaft \& Technologie,4, 2 (2012): 437-442

4. A. Hamzeh, S. Benjakul, T. Sae-Leaw, S. Sinthusamran, Effect of drying methods on gelatin from splendid squid (Loligo formosana) skins, Food Bioscience, 26 (2018): 96-103

5. J. Tkaczewska, M. Morawska, P. Kulawik, M. Zając, Characterization of carp (Cyprinus carpio) skin gelatin extracted using different pre-treatments method, Food Hydrocolloids, 81 (2018): 169-179

6. A. Aberoumand, Estimation of microbiological variations in minced lean fish products, World Journal of Fish and Marine Sciences, 2, 3 (2010): 204-207

7. T. Huang, Z.C. Tu, H. Wang, W. Liu, L. Zhang, Y. Zhang, X.C. ShangGuan, Comparison of rheological behaviors and nanostructure of bighead carp scales gelatin modified by different modification methods, Journal of Food Science and Technology, 54, 5 (2017): 1256-1265

8. P. Kittiphattanabawon, S. Benjakul, S. Sinthusamran, H. Kishimura, Gelatin from clown featherback skin: extraction conditions, Lebensmittel-Wissenschaft \& Technologie, 66 (2016): 186-192

9. P. Kittiphattanabawon, S. Benjakul, W. Visessanguan, F. Shahidi, Comparative study on characteristics of gelatin from the skins of brownbanded bamboo shark and blacktip shark as affected by extraction conditions, Food Hydrocolloids, 24, 2-3 (2010): 164-171

10. H. Fan, M.J. Dumont, B.K. Simpson, Extraction of gelatin from salmon (Salmo salar) fish skin using trypsin-aided process: optimization by PlackettBurman and response surface methodological approaches, Journal of Food Science and Technology, 54, 12 (2017): 4000-4008
11. E.T.A. Tümerkan, Ü. Cansu, G. Boran, J.M. Regenstein, F. Özoğul, Physiochemical and functional properties of gelatin obtained from tuna, frog and chicken skins, Food Chemistry, 287 (2019): 273-279

12. B.E. Abdelmalek, J. Gómez-Estaca, A. Sila, O. Martinez-Alvarez, M.C. Gómez-Guillén, S. Chaabouni-Ellouz, M.A. Ayadi, A. Bougatef, Characteristics and functional properties of gelatin extracted from squid (Loligo vulgaris) skin, Lebensmittel-Wissenschaft \& Technologie, 65 (2016): 924-931

13. S. Cho, J.R. Ahn, J.S. Koo, S.B. Kim, Physicochemical properties of gelatin from jellyfish Rhopilema hispidum, Fisheries and Aquatic Sciences, 17, 3 (2014): 299-304

14. U. Rodsuwan, B. Thumthanaruk, O. Kerdchoechuen, N. Laohakunjit, Functional properties of type A gelatin from jellyfish (Lobonema smithii), International Food Research Journal, 23, 2 (2016): 507-514

15. P. Chancharern, N. Laohakunjit, O. Kerdchoechuen, B. Thumthanaruk, Extraction of type A and type B gelatin from jellyfish (Lobonema smithii), International Food Research Journal, 23, 1 (2016): 419-424

16. Y.H.P. Hsieh, F.M. Leong, J. Rudloe, Jellyfish as food, Hydrobiologia, 451, 1-3 (2001): 11-17

17. L. Torri, F. Tuccillo, S. Bonelli, S. Piraino, A. Leone, The attitudes of Italian consumers towards jellyfish as novel food, Food Quality and Preference, 79 (2020): 103782

18. M.T. Pedersen, T.A. Vilgis, Soft matter physics meets the culinary arts: From polymers to jellyfish, International Journal of Gastronomy and Food Science, 16 (2019): 100135

19. P. Muangrod, V. Rungsardthong, S. Vatanyoopaisarn, Y. Tamaki, E. Kuraya, B. Thumthanaruk, Effect of wash cycle on physical and chemical properties of rehydrated jellyfish byproducts and jellyfish protein powder, Science, Engineering and Health Studies, 15 (2021): 21030004

20. A. Lueyot, V. Rungsardthong, S. Vatanyoopaisarn, P. Hutangura, B. Wonganu, P. Wongsa-Ngasri, S. Charoenlappani, S. Roytrakul, B. Thumthanaruk, Influence of collagen and some proteins on gel properties of jellyfish gelatin, PLOS One, 16, 6 (2021): e0253254

21. M.C. Gómez-Guillén, J. Turnay, M.D. FernándezDíaz, N. Ulmo, M.A. Lizarbe, P. Montero, Structural and physical properties of gelatin extracted from different marine species: a comparative study, Food Hydrocolloids, 16, 1 (2002): 25-34

22. W. Charoenchokpanich, V. Rungsardthong, S. Vatanyoopaisarn, B. Thumthanaruk, Y. Tamaki, Salt reduction in salted jellyfish (Lobonema smithii) using a mechanical washing machine, Science, 
Engineering and Health Studies, 14, 3 (2020): 184192

20. AOAC, Official Methods of Analysis of AOAC International (AOAC International, Maryland, USA, 2000)

20. C.S. James, Analytical Chemistry of Foods (Springer, London, 1995)

2ロ. S. Benjakul, M.T. Morrissey, Protein hydrolysates from Pacific whiting solid wastes, Journal of Agricultural and Food Chemistry, 45, 9 (1997): 3423-3430

20. GMIA, Standard methods for the sampling and testing of gelatins (Gelatin Manufacturers of America, Inc., New York, 1986)

2ロ. T. Klaiwong, P. Hutangura, S. Rutatip, P. WongsaNgasri, B. Thumthanaruk, Comparative properties of pepsin hydrolyzed jellyfish protein from salted jellyfish, Journal of Agricultural Science and Technology B, 4, 7 (2014): 555-564

2ロ. M. Omori, E. Nakano, Jellyfish fisheries in Southeast Asia, Hydrobiologia, 451, 1-3 (2001): 1926

૧૯. T. Zhang, R. Sun, M. Ding, L. Tao, L. Liu, N. Tao, $\mathrm{X}$. Wang, J. Zhong, Effect of extraction methods on the structural characteristics, functional properties, and emulsion stabilization ability of Tilapia skin gelatins, Food Chemistry, 328 (2020): 127114

30. H.D. Belitz, W. Grosch, P. Schieberle, Food Chemistry (Springer-Verlag Berlin Heidelberg, Berlin, 2009)
31. L.C. Sow, H. Yang, Effects of salt and sugar addition on the physicochemical properties and nanostructure of fish gelatin, Food Hydrocolloids, 45 (2015): 72-82

32. S. Silaprueng, B. Thumthanaruk, P. Wongsa-ngasri, Comparative functional properties of jellyfish (Lobonema smithii) protein hydrolysate as influenced by bromelain and hydrochloric acid, Journal of Food Science and Agricultural Technology, 1, 1 (2015): 171-176

33. B. Wonganu, Application of gelatin derived from waste tilapia scales to an antibiotic hydrogel pad, E3S Web of Conferences, 141 (2020): 03004

34. S. Benjakul, P. Kittiphattanabawon, J.M. Regenstein, in Food Biochemistry and Food Processing, edited by B.K. Simpson, L.M. Nollet, F. Toldrá, S. Benjakul, G. Paliyath, Y.H. Hui (John Wiley and Sons, Inc, Iowa, 2012), pp. 388-405

35. M. Jridi, R. Nasri, I. Lassoued, N. Souissi, A. Mbarek, A. Barkia, M. Nasri, Chemical and biophysical properties of gelatins extracted from alkali-pretreated skin of cuttlefish (Sepia officinalis) using pepsin, Food Research International, 54, 2 (2013): 1680-1687

36. R.E. Farrell, RNA Methodologies: A Laboratory Guide for Isolation and Characterization (Academic Press, San Diego, 1993)

37. H. Kchaou, N. Benbettaied, M. Jridi, M. Nasri, F. Debeaufort, Influence of Maillard reaction and temperature on functional, structure and bioactive properties of fish gelatin films, Food Hydrocolloids, 97 (2019): 105196 